\title{
Association of depression symptom severity with short-term risk of an initial hospital encounter in adults with major depressive disorder
}

Jennifer Voelker ( $\sim$ JVoelke4@its.jnj.com )

Janssen Scientific Affairs LLC

Kun Wang

Janssen Scientific Affairs LLC

Wenze Tang

Janssen Scientific Affairs LLC

Jinghua He

Janssen Scientific Affairs LLC

Ella Daly

Janssen Research and Development Titusville

Christopher D Pericone

Janssen Scientific Affairs LLC

John J Sheehan

Janssen Scientific Affairs LLC

\section{Research article}

Keywords: Major depressive disorder, depression symptom severity, PHQ-9 assessment, healthcare resource utilization, hospital encounter, natural language processing

Posted Date: August 28th, 2020

DOI: https://doi.org/10.21203/rs.3.rs-61612/v1

License: (c) (1) This work is licensed under a Creative Commons Attribution 4.0 International License.

Read Full License

Version of Record: A version of this preprint was published at BMC Psychiatry on May 17th, 2021. See the published version at https://doi.org/10.1186/s12888-021-03258-3. 


\section{Abstract}

\section{Background}

Despite the availability of pharmacologic and nonpharmacologic treatment options, depression continues to be one of the leading causes of disability worldwide. The impact of depression symptom severity on short-term risk of hospitalization is not well established in the literature. This study evaluates the degree to which depression symptom severity in patients diagnosed with MDD is associated with risk of an initial hospital encounter (ER visit or hospitalization) in the short-term following an outpatient PHQ9 assessment.

Methods

Adult patients ( $\geq 18$ years of age) with $\geq 1$ PHQ-9 assessment in an outpatient setting (index date) and $\geq 1$ MDD diagnosis within 6 months prior were included from the de-identified Optum Electronic Health Record database (April 2016-June 2019). Patients were categorized based on PHQ-9 scores obtained by natural language processing. Crude rates and adjusted absolute risks of all-cause, MDD-related, and suicidal ideation (SI)/suicide attempt (SA)-related hospital encounters within 30 days of patients' PHQ-9 assessments were evaluated.

Results

The study population consisted of 280145 patients with MDD and $\geq 1$ PHQ-9 assessment in an outpatient setting. Based on PHQ-9 scores, $26.9 \%$ of patients were categorized as having none/minimal depression symptom severity, $16.4 \%$ as mild, $24.7 \%$ as moderate, $19.6 \%$ as moderately severe, and $12.5 \%$ as severe. Among patients with none/minimal, mild, moderate, moderately severe, and severe depression, the adjusted absolute short-term risks of an initial all-cause hospital encounter were $3.9 \%, 4.3 \%, 4.9 \%$, $5.7 \%$, and $6.7 \%$, respectively; of a MDD-related hospital encounter they were $0.8 \%, 1.0 \%, 1.3 \%, 1.6 \%$, and $2.2 \%$, respectively; of a SI/SA-related hospital encounter they were $0.1 \%, 0.1 \%, 0.1 \%, 0.3 \%$, and $0.8 \%$, respectively

Conclusions

These study findings indicate that depression symptom severity is a key driver of short-term risk of hospital encounters, emphasizing the need of timely interventions that can ameliorate depression symptom severity.

\section{Background}

Major depressive disorder (MDD) is a common and frequently recurrent psychiatric condition characterized by significant social and functional impairment [1, 2]. In 2018, 7.2\% of adults in the United States reported they had experienced at least one major depressive episode in the prior year, with $65 \%$ reporting severe impairment [3]. In addition to being associated with increased risk of poor health 
outcomes, including early onset and increased severity of chronic comorbid diseases and hospitalization [4-6], MDD is associated with an increased risk of suicidal ideation (SI) and suicide attempt (SA) [7, 8], as well as all-cause mortality [6].

The American Psychiatric Association has established 9 symptom criteria for diagnosis of MDD in the Diagnostic and Statistical Manual of Mental Disorders, Fifth Edition (DSM-5) [9]; the number, frequency, and intensity of symptoms can range from none/minimal to severe $[9,10]$. Clinicians may use validated instruments to assess symptom severity to manage treatment appropriately. The self-administered 9-item Patient Health Questionnaire (PHQ-9) is such an instrument; it is aligned with the DSM- 5 symptom criteria for MDD and has been validated as a useful tool for the diagnosis of MDD and as a reliable and valid measure of depression symptom severity by a multitude of studies [11-13]. The PHQ-9 total score ranges from 0 to 27 and levels of depression symptom severity are typically categorized as the following: none/minimal (0-4), mild (5-9), moderate (10-14), moderately severe (15-19) and severe (20-27) [11]. In 2016, the US Preventive Services Task Force (USPSTF) recommended routine screening for depression among adults in the US and the PHQ-9 as a suggested instrument [14].

The most recent data available, which was collected prior to 2016 USPSTF routine depression screening recommendations, shows that screening for depression in the primary care setting in the US has in the past been widely underused [15, 16]. Based on National Ambulatory Care Surveys (NACS), Samples et al reported only a $3.0 \%$ rate during years 2005 to 2015 of depression screening among visits to outpatient physician offices in the US [15]; the rate was reported at $4.2 \%$ in another study of physician-patient encounters based on 2012-2013 NACS data [16]. Patients with acute worsening of depression symptoms may present to the emergency room (ER), and the underuse of outpatient depression screening may contribute to this presentation. A study based on data from the Nationwide Emergency Department Sample reported that in 2014, ER visits for depression had increased by nearly $26 \%$ since 2006 in the US; over half of such ER visits in 2014 led to an inpatient stay that lasted on average 5.6 days [5]. In years 2014-2015 in the US, the average inpatient stay for MDD was 6 days with an average cost of $\$ 6713$ [17]. The growing burden of mental illness on the healthcare system in the US is detailed in the 2017 report of the National Council for Behavioral Health Medical Director Institute, which notes that across all care settings (inpatient, outpatient, community, workforce, etc) there is insufficient access for those who are mentally ill [18]. In particular, there is an extensive and widespread psychiatric inpatient bed shortage, which contributes to exorbitantly long wait times in the ER for psychiatric care (up to 23 hours on average for some dispositions) [18].

A better understanding of the impact of depression symptom severity on future use of healthcare resources, specifically that provided by hospitals, may be helpful to better determine the most appropriate targeted interventions that can be implemented earlier in the course of onset of worsening depression symptoms. A few small-scale studies conducted in the US have found depression severity to impact use of healthcare resources, including hospital encounters and mental health services [19,20]. Adekkanattu et al recently developed a natural language processing (NLP) method to extract PHQ-9 scores from unstructured data in electronic health records (EHRs) that exhibited high accuracy (97\%) and sensitivity 
(98\%) compared to a reference standard to identify patients with MDD and had utility for stratifying patients by depression severity [21]. Utilizing a similar NLP approach to extract PHQ-9 assessment data developed by Optum (Eden Prairie, MN), in this study we evaluated whether depression symptom severity in a large US population of patients diagnosed with MDD is associated with risk of an initial hospital encounter in the short-term following a PHQ-9 assessment administered in an outpatient care setting.

\section{Methods}

\section{Data source and study population}

Utilizing data from the Optum ${ }^{\circledR}$ EHR database, this study retrospectively analyzed healthcare resource utilization (HRU) outcomes of patients diagnosed with MDD who had a PHQ-9 assessment. The Optum EHR database is a multidimensional database that contains information on outpatient visits, diagnostic procedures, medications, laboratory results, hospitalizations, clinical notes, and patient outcomes primarily from integrated delivery networks. The database includes data from $>80$ million patients, with $\geq 7$ million patients from each US census region that is captured by a network of $\geq 140000$ providers at $>700$ hospitals and $>7000$ clinics. Both structured and unstructured data from the Optum EHR database were used in the analyses of this study. The structured data included demographic information, clinical characteristics, and HRU. PHQ-9 scores were determined from unstructured data derived from EHR note fields using Optum's proprietary NLP. All patient data contained in the Optum EHR database are deidentified and in compliance with the Health Insurance Portability and Accountability Act.

Adult patients ( $\geq 18$ years of age) with $\geq 1$ record of a PHQ-9 assessment in an outpatient care setting during April 2016 to June 2019 were included from the de-identified Optum EHR database. Individuals may have had multiple PHQ-9 assessments and only the first such assessment was selected with the corresponding date defined as the index date. Patients were required to have $\geq 1$ diagnosis of MDD (International Classification of Diseases, $10^{\text {th }}$ revision [ICD-10] codes provided in supplementary material) on or during the 6 months prior to the index date and $\geq 6$ months of health activity in the Optum EHR database preceding the index date. The baseline period was defined as the 6 months prior to the index date; the follow-up period was defined as the 30 days following the index date. Patients were excluded if they had a diagnosis during any timepoint in the study period of bipolar disorder, schizophrenia or other non-mood related psychotic disorders, dementia, and intellectual disability.

\section{Assessment of depression severity}

Using Optum's NLP of PHQ-9 assessments, patients were assigned to the following study cohorts based on depression symptom severity level as defined by Kroenke et al [11]: None/minimal = score 0 to 4, mild $=$ score 5 to 9 , moderate $=$ score 10 to 14 , moderately severe $=$ score 15 to 19 , and severe = score 20 to 27 . If multiple PHQ-9 assessments were recorded on the same day, the highest score was used to categorize patients into study cohorts. 
PHQ-9 scores in the Optum EHR database are extracted from physician notes via NLP. We excluded original values that appeared invalid using criteria defined in collaboration with Optum. Optum further ascertained the accuracy of the remaining PHQ-9 scores in 100 random samples in comparison to manual curation. After matching by subject ID and date, 99 out of the 100 NLP-extracted PHQ-9 scores matched exactly to the manually curated PHQ-9 scores.

\section{Patient demographics and clinical characteristics}

Patient demographics, including age, gender, race, ethnicity, US geographic region of residence, and insurance type, and clinical characteristics were evaluated for each patient eligible for the study during the baseline period or on the index date and are reported for the overall study population and stratified by depression symptom severity level study cohorts. The clinical characteristics evaluated included smoking status, past SI, past SA, Elixhauser comorbidities and index score (nonpsychiatric) [22], and psychiatric comorbidities, based on the DSM-5 [9].

\section{HRU outcome measurements}

During the 30 days following patients' PHQ-9 assessments (ie, in the short-term), the proportions of patients with initial all-cause, MDD-related, and SI/SA-related hospital encounters were evaluated. MDDrelated HRU was based on ICD-10 codes in any position of discharge records. SI/SA-related HRU was based on ICD-10 codes described by Hedegaard et al [23] (provided in supplementary material).

\section{Statistical analyses}

Descriptive statistics were used to summarize demographics, clinical characteristics, and crude rates of HRU outcomes with means and standard deviations (SDs) for continuous variables and counts and percentages for categorical variables. A marginal structural model was created using a generalized linear model with binomial distribution and stabilized inverse probability weighting to estimate adjusted absolute risks at each depression symptom severity level under identity link and causal risk ratios of HRU outcomes across the depression symptom severity levels under log link (risk ratio [RR] with 95\% confidence intervals [Cl] were reported). Stabilized inverse probability weights were generated with multinomial logistic regression, adjusting for baseline demographics and clinical characteristics (ie, age, gender, race, ethnicity, US geographic region of residence, insurance type, smoking status, and nonpsychiatric individual Elixhauser comorbidities) as confounders [24, 25].

\section{Results}

\section{Study population}

The overall study population consisted of 280145 patients with MDD and $\geq 1$ PHQ-9 assessment in an outpatient care setting; $26.9 \%$ were categorized as having none/minimal depression symptom severity, $16.4 \%$ as mild, $24.7 \%$ as moderate, $19.6 \%$ as moderately severe, and $12.5 \%$ as severe. Demographics and selected clinical characteristics of the overall patient population and study cohorts stratified by 
depression symptom severity level are shown in Table 1. As depression symptom severity level increased, mean ages decreased across the study cohorts (none/minimal: 53.7 years; mild: 48.8 years; moderate: 47.1 years; moderately severe: 44.0 years; severe: 42.6 years, $p<0.001)$; correspondingly, the distribution of patients shifted to younger age groups. Across the study cohorts, approximately $72 \%-73 \%$ of patients were female, $80 \%-89 \%$ were Caucasian, $60 \%-68 \%$ had residence in the Midwest, and $21 \%-30 \%$ had commercial insurance coverage.

In study cohorts with greater depression symptom severity, the proportions of patients who were African American, Asian, and other races were higher than observed in study cohorts with lower depression symptom severity; similarly, the proportions of patients with Hispanic ethnicity were also higher in study cohorts with greater depression symptom severity. The proportions of patients with Medicaid coverage also were higher among study cohorts with moderate (4.7\%), moderately severe (5.7\%), and severe (7.2\%) depression than among study cohorts with lower levels of depression symptom severity $(2.0 \%-3.0 \%)$.

More patients with moderate (SI: $1.3 \%$; SA: $0.5 \%$ ), moderately severe (SI: $1.8 \%$; SA: $0.6 \%$ ), and severe (SI: $3.7 \%$; SA: $0.9 \%$ ) depression had documentation of past SI and SA compared to study cohorts with lower levels of depression symptom severity. Among the overall patient population, the mean Elixhauser index score was 13.4; this mean score decreased as depression symptom severity level increased. The comorbid psychiatric disorder that was the most prevalent among the overall study population was anxiety disorder (51.3\%), which increased in prevalence as depression symptom severity level increased.

\section{HRU outcome measurements}

The crude rates and adjusted absolute risks of all-cause, MDD-related, and SI/SA-related initial hospital encounters in the short-term following a PHQ-9 assessment are shown in Table 2 and Figure 1, respectively. Across all the evaluated types of initial hospital encounters in the short-term following a PHQ-9 assessment, crude rates increased with the level of depression symptom severity. When accounting for differences in baseline characteristics that may impact HRU, the adjusted results were consistent with the crude results. Among patients with none/minimal, mild, moderate, moderately severe, and severe depression, the adjusted absolute risks $(95 \% \mathrm{Cl})$ of an all-cause hospital encounter were $3.9 \%$ (3.7\%-4.0\%), 4.3\% (4.1\%-4.5\%), 4.9\% (4.7\%-5.0\%), 5.7\% (5.5\%-5.9\%), and 6.7\% (6.4\%-6.9\%), respectively; of an MDD-related hospital encounter they were $0.8 \%$ (0.7\%-0.8\%), 1.0\% (0.9\%-1.1\%), $1.3 \%(1.2 \%-1.4 \%), 1.6 \%$ (1.5\%-1.7\%), and $2.2 \%(2.1 \%-2.3 \%)$, respectively; and of an SI/SA-related hospital encounter they were $0.1 \%(0.0 \%-0.1 \%), 0.1 \%(0.1 \%-0.2 \%), 0.1 \%(0.1 \%-0.2 \%), 0.3 \%(0.2 \%-0.3 \%)$, and $0.8 \%(0.7-0.8 \%)$.

The adjusted RRs of all-cause, MDD-related, and SI/SA-related initial hospital encounters in the short-term following a PHQ-9 assessment are shown in Figure 2 (each depression symptom severity level cohort compared to none/minimal) and supplementary Table 1 (all depression symptom severity level cohort comparisons). Compared to patients with none/minimal depression symptom severity, those with mild depression had an $11 \%$ increased risk of an all-cause initial hospital encounter in the short-term following their PHQ-9 assessment, those with moderate depression had a $26 \%$ increased risk, those with moderately severe depression had a $46 \%$ increased risk, and those with severe depression had a $72 \%$ 
increased risk (all comparisons were $p<0.001$ ). This trend of a significantly increased risk of an initial hospital encounter associated with increased depression symptom severity level vs. none/minimal was consistent for MDD-related and SI/SA-related hospital encounters. Furthermore, the increased risk of an initial all-cause hospital encounter was apparent across all depression symptom severity level comparisons (ie, moderate vs. mild, moderately severe vs. mild, severe vs. mild, etc.) and consistent for MDD- and SI/SA-related hospital encounters.

\section{Discussion}

This is the first large-scale study in the US to evaluate the association between depression symptom severity and short-term risk of initial hospital encounters. Among more than 280000 US adult patients diagnosed with MDD who had a PHQ-9 assessment in an outpatient care setting, $26.9 \%$ were categorized as having none/minimal depression symptom severity, $16.4 \%$ as mild, $24.7 \%$ as moderate, $19.6 \%$ as moderately severe, and $12.5 \%$ as severe. A notable finding of this study was the nearly stepwise manner that depression symptom severity was associated with an increased risk of an MDD-related hospital encounter in the short-term following a PHQ-9 assessment; the increased risk ranged from $34 \%$ to $189 \%$ among those with mild to severe depression symptom severity compared to those with none/minimal. Patients with moderately severe and severe levels of depressive symptoms also had greater than $300 \%$ and $1000 \%$, respectively, increased risk of an SI/SA-related hospital encounter compared to those categorized as having none/minimal, symptom severity, which may be considered graphically to be more of an exponential than stepwise increase. These study findings were obtained after adjustment for differences in patient demographics and clinical characteristics and indicate that depression symptom severity is a key driver of the short-term risk of presentation to the hospital setting. Moreover, our study findings imply that taking steps towards improving depression symptoms, even if by only one severity category, may be helpful to incrementally reduce the risk of short-term HRU, particularly among those in the highest severity categories.

The findings of this study significantly contribute to the accumulating evidence of the association of depression symptom severity with increased HRU in the US observed in a few other studies conducted on a considerably smaller scale $[19,20]$. Beiser et al conducted a prospective cohort study of 999 adults who presented to the ER for care other than for a psychiatric illness at a single US academic medical center in 2015 [19]. Based on depression diagnostic screening and depression severity measurement administered via a tablet computer during the ER visit, patients identified with MDD (27\%) had a significantly greater risk of a subsequent ER visit (61\% increased risk) and hospitalization (49\% increased risk) during the 1 year follow-up period than those without MDD; furthermore, each $10 \%$ increase in MDD severity was associated with a $10 \%$ greater relative risk of a subsequent hospital encounter [19]. In another study of 539 individuals who self-rated their MDD using the Quick Inventory of Depressive Symptomatology SelfReport (2001-2002), 13.8\% were classified as having mild depression, $38.5 \%$ as moderate, and $47.7 \%$ as severe; those with moderate and severe MDD used mental health services to a greater extent than those with mild disease, as well as had greater prevalence of unemployment, reduced work productivity, and disability [20]. A relatively larger study of 10,443 individuals in Stockholm, Sweden (1998-2014) reported 
that those with subsyndromal, mild, moderate, and severe depression, according to scores on the Major Depression Inventory, had higher incidence rates of mental health-related hospitalizations and outpatient care visits than non-depressed individuals; similar to our study, Sun et al reported that as depression severity level increased, so did the rate of HRU [26].

Another remarkable finding of this study pertains to the association of increased depression symptom severity with increased risk of all-cause hospital encounters. Compared to patients with MDD and none to minimal depression symptom severity, those with mild had an $11 \%$ increased risk of an all-cause hospital encounter in the short-term following their PHQ-9 assessment, those with moderate had a $26 \%$ increased risk, those with moderately severe had a $46 \%$ increased risk, and those with severe had a $72 \%$ increased risk. This stepwise association of depression symptom severity level with increased relative risk of an allcause hospital encounter in the short-term following a PHQ-9 assessment was observed after adjustment for age and the presence of Elixhauser comorbidities. Reviewed in Kessler et al [6], a number of other studies have previously shown that MDD is associated with early onset and/or increased severity of several comorbid chronic illnesses, including cardiovascular disease, diabetes, respiratory illnesses, and chronic pain. Reported in a systematic review of several studies, depressive symptoms are a significant predictor of general hospital admissions for non-psychiatric reasons (RR: 1.36, 95\% Cl: 1.28-1.44), as well as longer inpatient lengths of stay and higher readmission risk [27]. The findings of our study add to this existing evidence of the association of MDD with increased HRU for non-psychiatric reasons by portraying the impact of increased depression symptom severity on the increased likelihood of all-cause $\mathrm{HRU}$ in the short-term. The reasons surrounding the association of depression symptom severity with greater utilization of healthcare resources in general are not well understood, but could be related to suboptimal treatment options, inadequate adherence to medications or treatments, a greater prevalence of chronic conditions (eg, substance abuse disorders, smoking history), lack of follow-up care by patients and/or providers, sociodemographic disparities, access to psychiatric care facilities, etc.

Two other studies conducted in the last decade in the US have also examined the distribution of patients with MDD across symptom severity categories based on PHQ-9 assessments, although they did not explore HRU to a significant extent [28, 29]. In a study of 1019 patients diagnosed with MDD (2006-2010 population sample from 9 US states in different geographic regions), Valuck found a generally similar distribution of patients with MDD across PHQ-9 score categories [28]. In another population of MDD patients in the US ( $N=315,2014-2016)$, Bushnell et al reported $6.7 \%$ of patients with none/minimal (PHQ9 score: 0-4), 26.7\% with mild (PHQ-9 score: 5-9), 21.9\% with moderate (PHQ-9 score: $10-14$ ), $27.6 \%$ with moderately severe (PHQ-9 score: 15-19), and 17.1\% with severe (PHQ-9 score: 20-27) depression [29]. In our study, PHQ-9 scores of patients diagnosed with MDD were documented in EHRs, and therefore likely do not fully represent the distribution of severity categories among the overall population of patients with MDD in the US, especially those who have not been diagnosed and/or are without access to routine healthcare. Furthermore, a large proportion of patients represented in this study were from the Midwest region of the US; this particular region also contributed disproportionately to the none/mild depression symptom severity category. These findings may suggest that the PHQ-9 is used more routinely and that there is greater access to depression treatment in the Midwest compared to other US regions. Additionally, 
African American patients with MDD disproportionately were in the highest depression symptom severity categories. Several factors could contribute to this finding, including reduced access to routine healthcare resources where lower severity MDD may be assessed and documented. Nevertheless, the distribution of MDD patients across the PHQ-9 categories observed in this analysis broadly matches that observed in other studies with much smaller populations $[28,29]$.

This study has strengths in that it included a very large population of patients diagnosed with MDD across the US who had a PHQ-9 assessment, a validated instrument for measuring depression symptom severity [11]. Since the PHQ-9 has been shown to have good agreement with clinician depression rating scales (eg, Hamilton Depression Rating Scale) commonly used in clinical trial settings [30], the population-level data herein may be useful to apply to clinical trial data for economic modeling and other treatment-related measurement purposes. Furthermore, Optum's NLP technology allowed for the timely extraction of large amount of PHQ-9 score data from complex clinical notes available in the EHRs. In addition, the marginal structural model (MSM) allowed us to identify the adjusted absolute risk at each level of severity level, which is not possible with conventional regression techniques. MSM is also agnostic about the effect modification by any covariates, therefore the relative risk estimates are not subject to model misspecification with respect to any product terms between depression severity and baseline covariates that could be possibly mis-specified in conventional regression techniques.

\section{Limitations of the study}

The findings of this study should be interpreted with the understanding of certain limitations. First, the Optum EHR database may not contain all patient interactions with their healthcare system, including visits for psychiatric care provided by specialists who do not contribute to EHRs within the database. Second, since depression severity varies over time, using a single time point measure as a proxy of a complex exposure trajectory may result in non-differential measurement error that biases our results towards the null. As an observational study, no causal relationship between depression symptom severity and short-term HRU can be affirmed; however, such a hypothesis is plausible and can guide actions since a randomization of similar populations is not possible. Also, since the findings were based on real-world data obtained from EHRs, there is the potential for inaccuracies in diagnosis codes, missing records, and erroneous PHQ-9 scores recorded by healthcare providers in the clinical notes. However, our validation process confirmed that the NLP technology generated accurate PHQ-9 score outputs. Further study using similar methodology across other EHR database sources is warranted.

\section{Conclusions}

This study of over 280000 adults with MDD in the US and a PHQ-9 assessment is the largest study to date to evaluate how depression symptom severity, recorded during an outpatient appointment, impacts the likelihood of presenting to a hospital in the short-term. The study findings highlight the nearly stepwise manner that depression symptom severity is associated with increased risk of all-cause and MDD-related hospital encounters in the 30 days following an outpatient PHQ-9 assessment. Furthermore, 
the short-term risk of a hospital encounter for suicidal behavior of patients categorized as having moderately severe and severe depression symptom severity was greatly increased even when compared to other patients with MDD with lower symptom severity. These findings emphasize the importance of routine depression screening and timely intervention with efficacious treatments, including pharmacotherapy, psychotherapy, and other types of individualized patient management strategies potentially implemented in the outpatient setting, as prevention tactics to mitigate the course of acute worsening of symptoms of MDD and reduce some of the burden currently incurred by hospital systems.

\section{Abbreviations}

Cl: Confidence interval

DSM-5: Diagnostic and Statistical Manual of Mental Disorders, Fifth Edition

EHR: Electronic health record

ER: Emergency room

HRU: Healthcare resource utilization

ICD-10: International Classification of Diseases, $10^{\text {th }}$ revision

MDD: Major depressive disorder

MSM: Marginal structural model

NACS: National Ambulatory Care Survey

NLP: Natural language processing

PHQ-9: 9-item Patient Health Questionnaire

RR: Risk ratio

SA: Suicide attempt

SD: Standard deviation

Sl: Suicidal ideation

USPSTF: US Preventive Services Task Force

\section{Declarations}




\section{Ethics approval and consent to participate:}

All patient data contained with the Optum EHR database are de-identified and in compliance with the Health Insurance Portability and Accountability Act. Thus, no Institutional Review Board approval was required for this study.

\section{Consent to publish:}

All authors and Janssen Scientific Affairs, LLC have given consent to publish this manuscript.

\section{Availability of data and materials:}

All data for this study are contained within the article and online supplementary material; Elixhauser nonpsychiatric individual comorbidity data are available from the corresponding author on reasonable request.

\section{Competing interests:}

J Voelker, K Wang, W Tang, J He, E Daly, C Pericone, and JJ Sheehan are employees or previous employees of Janssen and may be stockholders in Johnson \& Johnson.

\section{Role of the funder/sponsor}

The sponsors had a primary role in the design and conduct of the study; collection, management, analysis, and interpretation of the data; preparation, review, and approval of the manuscript; and decision to submit the manuscript for publication.

\section{Funding:}

This study and preparation of this manuscript was sponsored by Janssen Scientific Affairs, LLC.

\section{Authors' contributions:}

Study concept and design: JV, KW, WT, ED, CH, JJS. Drafting of manuscript: JV, KW, WT, CP, JJS Critical reviews: All authors. Statistical analysis: JV, KW, WT, JH. Interpretation of data: JV, KW, JH, CP, JJS. Final version approval: All authors.

\section{Acknowledgements:}

Editorial support was provided by Jay Lin and Melissa Lingohr-Smith of Novosys Health, which was funded by Janssen Scientific Affairs, LLC. 


\section{References}

1. Spijker J, Graaf R, Bijl RV, Beekman ATF, Ormel J, Nolen WA. Functional disability and depression in the general population. Results from the Netherlands Mental Health Survey and Incidence Study (NEMESIS). Acta Psychiatr Scand. 2004;110:208-14.

2. Rhebergen D, Beekman AT, de Graaf R, Nolen WA, Spijker J, Hoogendijk WJ, Penninx BWJH. Trajectories of recovery of social and physical functioning in major depression, dysthymic disorder and double depression: a 3-year follow-up. J Affect Disord. 2010;124:148-56.

3. Substance Abuse and Mental Health Services Administration. Key substance use and mental health indicators in the United States: results from the 2018 National Survey on Drug Use and Health. 2019. HHS Publication No. PEP19-5068, NSDUH Series H-54. Rockville, MD: Center for Behavioral Health Statistics and Quality, Substance Abuse and Mental Health Services Administration. https://www.samhsa.gov/data/sites/default/files/cbhsqreports/NSDUHNationalFindingsReport2018/NSDUHNationalFindingsReport2018.pdf. Accessed 10 Apr 2020.

4. Moussavi S, Chatterji S, Verdes E, Tandon A, Patel V, Ustun B. Depression, chronic diseases, and decrements in health. Lancet. 2007;370:851-8.

5. Ballou S, Mitsuhashi S, Sankin LS, Petersen TS, Zubiago J, Lembo C, et al. Emergency department visits for depression in the United States from 2006 to 2014. Gen Hosp Psychiatry. 2019;59:14-9.

6. Kessler RC. The costs of depression. Psychiatr Clin North Am. 2012;35:1-14.

7. Coryell W, Young EA. Clinical predictors of suicide in primary major depressive disorder. J Clin Psychiatry. 2005;66:412-17.

8. Holma KM, Melartin TK, Haukka J, Holma IAK, Sokero TP, Isometsä ET. Incidence and predictors of suicide attempts in DSM-4 major depressive disorder: a five-year prospective study. Am J Psychiatry. 2010;167:801-8.

9. American Psychiatric Association. Diagnostic and Statistical Manual of Mental Disorders: Diagnostic and Statistical Manual of Mental Disorders, Fifth Edition (DSM-5). American Psychiatric Association: Arlington, VA; 2013.

10. Hasin DS, Sarvet AL, Meyers JL, Saha TD, Ruan WJ, Stohl M, Grant BF. Epidemiology of adult DSM-5 major depressive disorder and its specifiers in the United States. JAMA Psychiatry. 2018;75:336-46.

11. Kroenke K, Spitzer RL, Williams BV. The PHQ-9. J Gen Intern Med. 2001;16:606-13.

12. Löwe $B$, Unützer J, Callahan, Perkins AJ, Kroenke K. Monitoring depression treatment outcomes with the patient health questionnaire-9. Med Care. 2004;42:1194-201.

13. Levis B, Benedetti A, Thombs BD. DEPRESsion Screening Data (DEPRESSD) Collaboration. Accuracy of Patient Health Questionnaire-9 (PHQ-9) for screening to detect major depression: individual participant data meta-analysis. BMJ. 2019;365:I1476.

14. Siu AL, US Preventive Services Task Force (USPSTF); Bibbins-Domingo K, Grossman DC, Baumann LC, Davidson KW, et al. Screening for depression in adults: US Preventive Services Task Force 
Recommendation Statement. JAMA. 2016;315:380-7.

15. Samples H, Stuart EA, Saloner B, Barry CL, Mojtabai R. The role of screening in depression diagnosis and treatment in a representative sample of US primary care visits. J Gen Intern Med. 2020;35:1220.

16. Akincigil A, Matthews EB. National rates and patterns of depression screening in primary care: results from 2012 and 2013. Psychiatr Serv. 2017;68:660-6.

17. Citrome L, Jain R, Tung A, Lansman-Blumberg PB, Kramer K, Ali S. Prevalence, treatment patterns, and stay characteristics associated with hospitalizations for major depressive disorder. J Affect Disord. 2019;249:378-84.

18. National Council Medical Director Institute. The psychiatric shortage: causes and solutions. March 28. 2017. Washington DC: National Council for Behavioral Health. https://www.thenationalcouncil.org/wp-content/uploads/2017/03/Psychiatric-Shortage_NationalCouncil-.pdf?daf=375ateTbd56. Accessed 10 Apr 2020.

19. Beiser DG, Ward CE, Vu M, Laiteerapong N, Gibbons RD. Depression in emergency department patients and association with health care utilization. Acad Emerg Med. 2019;26:878-88.

20. Birnbaum HG, Kessler RC, Kelley D, Ben-Hamadi R, Joish VN, Greenberg PE. Employer burden of mild, moderate, and severe major depressive disorder: mental health services utilization and costs, and work performance. Depress Anxiety. 2010;27:78-89.

21. Adekkanattu P, Sholle ET, DeFerio J, Pathak J, Johnson SB, Campion TR Jr Ascertaining depression severity by extracting Patient Health Questionnaire-9 (PHQ-9) scores from clinical notes. AMIA Annu Symp Proc. 2018;2018:147-56.

22. Elixhauser C Software, version 3.7. Healthcare Cost and Utilization Project (HCUP). October 2015. https://www.hcup-us.ahrq.gov/toolssoftware/comorbidity/comorbidity.jsp\#download. Accessed April 10, 2020.

23. Hedegaard H, Schoenbaum M, Claassen C, Crosby A, Holland K, Proescholdbell S. Issues in developing a surveillance case definition for nonfatal suicide attempt and intentional self-harm using International Classification of Diseases, Tenth revision, Clinical Modification (ICD-10-CM) coded data. Natl Health Stat Report. 2018;1-19.

24. Hernán MA, Robins JM. Causal inference: what If. Boca Raton: Chapman \& Hall/CRC; 2020.

25. Li S, Okereke OI, Chang SC, Kawachi I, VanderWeele TJ. Religious service attendance and lower depression among women-a prospective cohort study. Ann Behav Med. 2016;50:876-84.

26. Sun Y, Möeller J, Lundin A, Wong SYS, Yip BHK, Forsell Y. Utilization of psychiatric care and antidepressants among people with different severity of depression: a population-based cohort study in Stockholm, Sweden. Soc Psychiatry Psychiatr Epidemiol. 2018;53:607-15.

27. Prina AM, Cosco TD, Dening T, Beekman A, Brayne C, Huisman M. The association between depressive symptoms in the community, non-psychiatric hospital admission and hospital outcomes: a systematic review. J Psychosom Res. 2015;78:25-33. 
28. Valuck RJ, Anderson HO, Libby AM, Brandt E, Bryan C, Allen RR, et el. Enhancing electronic health record measurement of depression severity and suicide ideation: a Distributed Ambulatory Research in Therapeutics Network (DARTNet) study. J Am Board Fam Med. 2012;25:582-93.

29. Bushnell DM, McCarrier KP, Bush EN, Abraham L, Jamieson C, McDougall F, et al. Symptoms of major depressive disorder scale: performance of a novel patient-reported symptom measure. Value Health. 2019;22:906-15.

30. Zimmerman M, Walsh E, Friedman M, Boerescu DA, Attiullah N. Are self-report scales as effective as clinician rating scales in measuring treatment response in routine clinical practice. $J$ Affect Disord. 2018;225:449-52.

\section{Tables}

Table 1 Demographics and selected clinical characteristics of overall patient population and study cohorts 


\begin{tabular}{|c|c|c|c|c|c|c|}
\hline & $\begin{array}{l}\text { Overall } \\
\text { Population }\end{array}$ & None/Minimal & Mild & Moderate & $\begin{array}{l}\text { Moderately } \\
\text { Severe }\end{array}$ & Severe \\
\hline & $N(\%)$ & $N(\%)$ & $N(\%)$ & $N(\%)$ & $N(\%)$ & $N(\%)$ \\
\hline & $\begin{array}{l}280145 \\
(100)\end{array}$ & 75227 (26.9) & $\begin{array}{l}45 \\
857 \\
(16.4)\end{array}$ & $\begin{array}{l}69325 \\
(24.7)\end{array}$ & $\begin{array}{l}54772 \\
(19.6)\end{array}$ & $\begin{array}{l}34 \\
964 \\
(12.5)\end{array}$ \\
\hline \multicolumn{7}{|l|}{ Age (years) } \\
\hline Mean (SD) & $48.0(17.6)$ & 53.7(17.2) & $\begin{array}{l}48.8 \\
(17.5)\end{array}$ & $\begin{array}{l}47.1 \\
(17.6)\end{array}$ & $44.0(16.9)$ & $\begin{array}{l}42.6 \\
(15.9)\end{array}$ \\
\hline \multicolumn{7}{|l|}{ Age distribution } \\
\hline $18-25$ years & $\begin{array}{l}36211 \\
(12.9)\end{array}$ & $5410(7.2)$ & $\begin{array}{l}5192 \\
(11.3)\end{array}$ & $\begin{array}{l}9608 \\
(13.9)\end{array}$ & $\begin{array}{l}9653 \\
(17.6)\end{array}$ & $\begin{array}{l}6348 \\
(18.2)\end{array}$ \\
\hline 26-34 years & $\begin{array}{l}40319 \\
(14.4)\end{array}$ & 7357 (9.8) & $\begin{array}{l}6354 \\
(13.9)\end{array}$ & $\begin{array}{l}10690 \\
(15.4)\end{array}$ & $\begin{array}{l}9480 \\
(17.3)\end{array}$ & $\begin{array}{l}6438 \\
(18.4)\end{array}$ \\
\hline 35-44 years & $\begin{array}{l}44813 \\
(16.0)\end{array}$ & 10095 (13.4) & $\begin{array}{l}7605 \\
(16.6)\end{array}$ & $\begin{array}{l}11296 \\
(16.3)\end{array}$ & $\begin{array}{l}9407 \\
(17.2)\end{array}$ & $\begin{array}{l}6410 \\
(18.3)\end{array}$ \\
\hline 45-54 years & $\begin{array}{l}49505 \\
(17.7)\end{array}$ & 12890 (17.1) & $\begin{array}{l}8131 \\
(17.7)\end{array}$ & $\begin{array}{l}11988 \\
(17.3)\end{array}$ & $\begin{array}{l}9795 \\
(17.9)\end{array}$ & $\begin{array}{l}6701 \\
(19.2)\end{array}$ \\
\hline 55-64 years & $\begin{array}{l}53410 \\
(19.1)\end{array}$ & $16422(21.8)$ & $\begin{array}{l}8986 \\
(19.6)\end{array}$ & $\begin{array}{l}12590 \\
(18.2)\end{array}$ & $\begin{array}{l}9531 \\
(17.4)\end{array}$ & $\begin{array}{l}5881 \\
(16.8)\end{array}$ \\
\hline $65+$ years & $\begin{array}{l}55887 \\
(19.9)\end{array}$ & 23053 (30.6) & $\begin{array}{l}9589 \\
(20.9)\end{array}$ & $\begin{array}{l}13153 \\
(19.0)\end{array}$ & $\begin{array}{l}6906 \\
(12.6)\end{array}$ & $\begin{array}{l}3186 \\
(9.1)\end{array}$ \\
\hline \multicolumn{7}{|l|}{ Gender } \\
\hline Female & $\begin{array}{l}202990 \\
(72.5)\end{array}$ & 54572 (72.5) & $\begin{array}{l}33 \\
256 \\
(72.5)\end{array}$ & $\begin{array}{l}49886 \\
(72.0)\end{array}$ & $\begin{array}{l}39766 \\
(72.6)\end{array}$ & $\begin{array}{l}25 \\
510 \\
(73.0)\end{array}$ \\
\hline Male & $\begin{array}{l}77155 \\
(27.5)\end{array}$ & 20655 (27.5) & $\begin{array}{l}12 \\
601 \\
(27.5)\end{array}$ & $\begin{array}{l}19439 \\
(28.0)\end{array}$ & $\begin{array}{l}15006 \\
(27.4)\end{array}$ & $\begin{array}{l}9454 \\
(27.0)\end{array}$ \\
\hline \multicolumn{7}{|l|}{ Race } \\
\hline Caucasian & $\begin{array}{l}238847 \\
(85.3)\end{array}$ & 66866 (88.9) & $\begin{array}{l}39 \\
905 \\
(87.0)\end{array}$ & $\begin{array}{l}58925 \\
(85.0)\end{array}$ & $\begin{array}{l}45316 \\
(82.7)\end{array}$ & $\begin{array}{l}27 \\
835 \\
(79.6)\end{array}$ \\
\hline African American & $\begin{array}{l}21961 \\
(7.8)\end{array}$ & 4789 (6.4) & $\begin{array}{l}3000 \\
(6.5)\end{array}$ & $\begin{array}{l}5270 \\
(7.6)\end{array}$ & $5036(9.2)$ & $\begin{array}{l}3866 \\
(11.1)\end{array}$ \\
\hline Asian & 2475 (0.9) & $530(0.7)$ & $\begin{array}{l}390 \\
(0.9)\end{array}$ & $619(0.9)$ & $534(1.0)$ & $\begin{array}{l}402 \\
(1.1)\end{array}$ \\
\hline Other & $\begin{array}{l}16862 \\
(6.0)\end{array}$ & $3042(4.0)$ & $\begin{array}{l}2562 \\
(5.6)\end{array}$ & $\begin{array}{l}4511 \\
(6.5)\end{array}$ & $3886(7.1)$ & $\begin{array}{l}2861 \\
(8.2)\end{array}$ \\
\hline
\end{tabular}




\section{Ethnicity}

Non-Hispanic

245525

(87.6)

$68592(91.2)$

$40 \quad 59055$

47260

29

$764 \quad(85.2)$

(86.3)

854

(88.9)

(85.4)

Hispanic

12915

$2183(2.9)$

$1991 \quad 3232$

(4.3)

(4.7)

$3312(6.0)$

2197

(4.6)

Unknown

21705

4452 (5.9)

31027038

(6.8) (10.2)

(6.3)

$4200(7.7) \quad 2913$

(8.3)

US geographic region

Midwest

177679

(63.4)

51231 (68.1)

$29 \quad 41902$

(60.4)

33758

21

178

(61.6)

610

(63.6)

(61.8)

Northeast

$20950 \quad 6289(8.4)$

4162

(9.1)

4776

(6.9)

$3582(6.5)$

2141

(6.1)

South

41404

9618 (12.8)

$6520 \quad 10964$

8985

(14.8)

(14.2)

(15.8)

(16.4)

5317

West

27161

$4953(6.6)$

$4123 \quad 8583$

(9.0) (12.4)

5603

(10.2)

(15.2)

(9.7)

$3136(4.2)$

$1874 \quad 3100$

(4.1)

(4.5)

2844 (5.2)

3899

(11.2)

Other/unknown

(4.6)

Insurance type

Commercial

72587

(25.9)

$16111(21.4)$

10

039

20285

16244

(29.7)

9908

(21.9)

Medicaid

11682

(4.2)

1467 (2.0)

1354

(3.0)

(29.3)

(28.3)

Medicare

28535

(10.2)

11406 (15.2)

4162

(9.1)

3242

(4.7)

$3095(5.7) \quad 2524$

(7.2)

Multiple

107215

(38.3)

32404 (43.1)

19

914

(43.4)

6732

(9.7)

4050 (7.4) $\quad 2185$

(6.2)

Other payer types

Uninsured

4267 (1.5) 1049 (1.4)

669

(1.5)

24474

(35.3)

18387

(33.6)

12

036

(34.4)

Missing

$2592(0.9) \quad 302(0.4)$

$278 \quad 695(1.0) \quad 746(1.4)$

$890(1.6)$

632

(1.8)

Missing

Unknown

$18271 \quad 3384(4.5)$

(6.5)

34996

(12.5)

$9104(12.1)$

(0.6)

$3094 \quad 4661$

(6.7) (6.7)

$4520(8.3)$

571

(1.6)

6347

8209

(13.8) (11.8)

6840

(12.5)

2612

(7.5) 
Smoking status

\begin{tabular}{|c|c|c|c|c|c|c|}
\hline Current smoker & $\begin{array}{l}77927 \\
(27.8)\end{array}$ & 16745 (22.3) & $\begin{array}{l}11 \\
424 \\
(24.9)\end{array}$ & $\begin{array}{l}19764 \\
(28.5)\end{array}$ & $\begin{array}{l}17299 \\
(31.6)\end{array}$ & $\begin{array}{l}12695 \\
(36.3)\end{array}$ \\
\hline Non-smoker & $\begin{array}{l}77626 \\
(27.7)\end{array}$ & $22181(29.5)$ & $\begin{array}{l}13 \\
424 \\
(29.3)\end{array}$ & $\begin{array}{l}18348 \\
(26.5)\end{array}$ & $\begin{array}{l}14847 \\
(27.1)\end{array}$ & $\begin{array}{l}8826 \\
(25.2)\end{array}$ \\
\hline History of smoking & $\begin{array}{l}124592 \\
(44.5)\end{array}$ & 36301 (48.3) & $\begin{array}{l}21 \\
009 \\
(45.8)\end{array}$ & $\begin{array}{l}31213 \\
(45.0)\end{array}$ & $\begin{array}{l}22626 \\
(41.3)\end{array}$ & $\begin{array}{l}13443 \\
(38.4)\end{array}$ \\
\hline Past SI & $4443(1.6)$ & $723(1.0)$ & $\begin{array}{l}548 \\
(1.2)\end{array}$ & 915 (1.3) & $964(1.8)$ & $\begin{array}{l}1293 \\
(3.7)\end{array}$ \\
\hline Past $S A$ & $1451(0.5)$ & $265(0.4)$ & $\begin{array}{l}229 \\
(0.5)\end{array}$ & $326(0.5)$ & $327(0.6)$ & $\begin{array}{l}304 \\
(0.9)\end{array}$ \\
\hline \multicolumn{7}{|l|}{ Elixhauser index score } \\
\hline Mean (SD) & $13.4(14.2)$ & $14.6(14.9)$ & $\begin{array}{l}13.4 \\
(14.2)\end{array}$ & $\begin{array}{l}13.2 \\
(14.3)\end{array}$ & $12.5(13.6)$ & $\begin{array}{l}12.4 \\
(13.4)\end{array}$ \\
\hline \multicolumn{7}{|l|}{$\begin{array}{l}\text { Psychiatric } \\
\text { comorbidities }^{a}\end{array}$} \\
\hline Anxiety disorders & $\begin{array}{l}143705 \\
(51.3)\end{array}$ & $33819(45.0)$ & $\begin{array}{l}23 \\
609 \\
(51.5)\end{array}$ & $\begin{array}{l}35923 \\
(51.8)\end{array}$ & $\begin{array}{l}29908 \\
(54.6)\end{array}$ & $\begin{array}{l}20 \\
446 \\
(58.5)\end{array}$ \\
\hline Sleep-wake disorders & $\begin{array}{l}43787 \\
(15.6)\end{array}$ & $12651(16.8)$ & $\begin{array}{l}7414 \\
(16.2)\end{array}$ & $\begin{array}{l}10979 \\
(15.8)\end{array}$ & $\begin{array}{l}7893 \\
(14.4)\end{array}$ & $\begin{array}{l}4850 \\
(13.9)\end{array}$ \\
\hline $\begin{array}{l}\text { Caffeine and nicotine } \\
\text { addictions }\end{array}$ & $\begin{array}{l}38999 \\
(13.9)\end{array}$ & $8086(10.7)$ & $\begin{array}{l}5716 \\
(12.5)\end{array}$ & $\begin{array}{l}10188 \\
(14.7)\end{array}$ & $\begin{array}{l}8790 \\
(16.0)\end{array}$ & $\begin{array}{l}6219 \\
(17.8)\end{array}$ \\
\hline $\begin{array}{l}\text { Trauma-and-stressor- } \\
\text { related disorders }\end{array}$ & $\begin{array}{l}26747 \\
(9.5)\end{array}$ & $5547(7.4)$ & $\begin{array}{l}4410 \\
(9.6)\end{array}$ & $\begin{array}{l}6534 \\
(9.4)\end{array}$ & $\begin{array}{l}5859 \\
(10.7)\end{array}$ & $\begin{array}{l}4397 \\
(12.6)\end{array}$ \\
\hline $\begin{array}{l}\text { All other substances } \\
\text { addiction (non- } \\
\text { caffeine and tobacco) }\end{array}$ & $\begin{array}{l}17926 \\
(6.4)\end{array}$ & $3796(5.0)$ & $\begin{array}{l}2968 \\
(6.5)\end{array}$ & $\begin{array}{l}4336 \\
(6.3)\end{array}$ & $3887(7.1)$ & $\begin{array}{l}2939 \\
(8.4)\end{array}$ \\
\hline
\end{tabular}

Across all listed comparisons of the study cohorts stratified by depression symptom severity level, $\mathrm{p}$ values were $<0.001$.

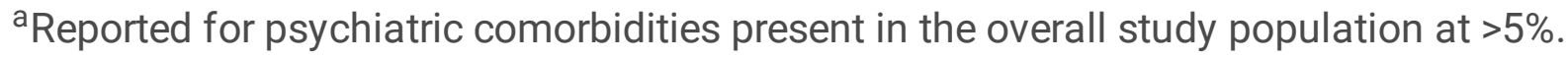

IQR: Interquartile range; MDD: Major depressive disorder; SA: Suicide attempt; SD: Standard deviation; SI: Suicidal ideation 
Table 2 Crude rates of all-cause, MDD-related, and SI/SA-related initial hospital encounters following a PHQ-9 assessment

\begin{tabular}{|llllll|}
\hline & None/Minimal & Mild & Moderate & $\begin{array}{l}\text { Moderately } \\
\text { severe }\end{array}$ & Severe \\
\hline No. of patients & 75227 & 45857 & 69325 & 54772 & 34964 \\
$\begin{array}{l}\text { Type of hospital encounter, } N \\
(\%)\end{array}$ & & & & & \\
\hline All-cause & $2746(3.7)$ & $\begin{array}{l}1927 \\
(4.2)\end{array}$ & $\begin{array}{l}3363 \\
(4.9)\end{array}$ & $3026(5.5)$ & 2369 \\
MDD-related & $591(0.8)$ & $\begin{array}{l}452 \\
(1.0)\end{array}$ & $921(1.3)$ & $813(1.5)$ & 776 \\
& & $52(0.1)$ & $96(0.1)$ & $149(0.3)$ & 299 \\
\hline SI/SA-related & $39(0.1)$ & & & & $(0.9)$ \\
\hline
\end{tabular}

MDD: Major depressive disorder; SA: Suicide attempt; SI: Suicidal ideation

\section{Figures}

aAll-cause $\quad$ MDD-related $\quad \square$ SI/SA-related

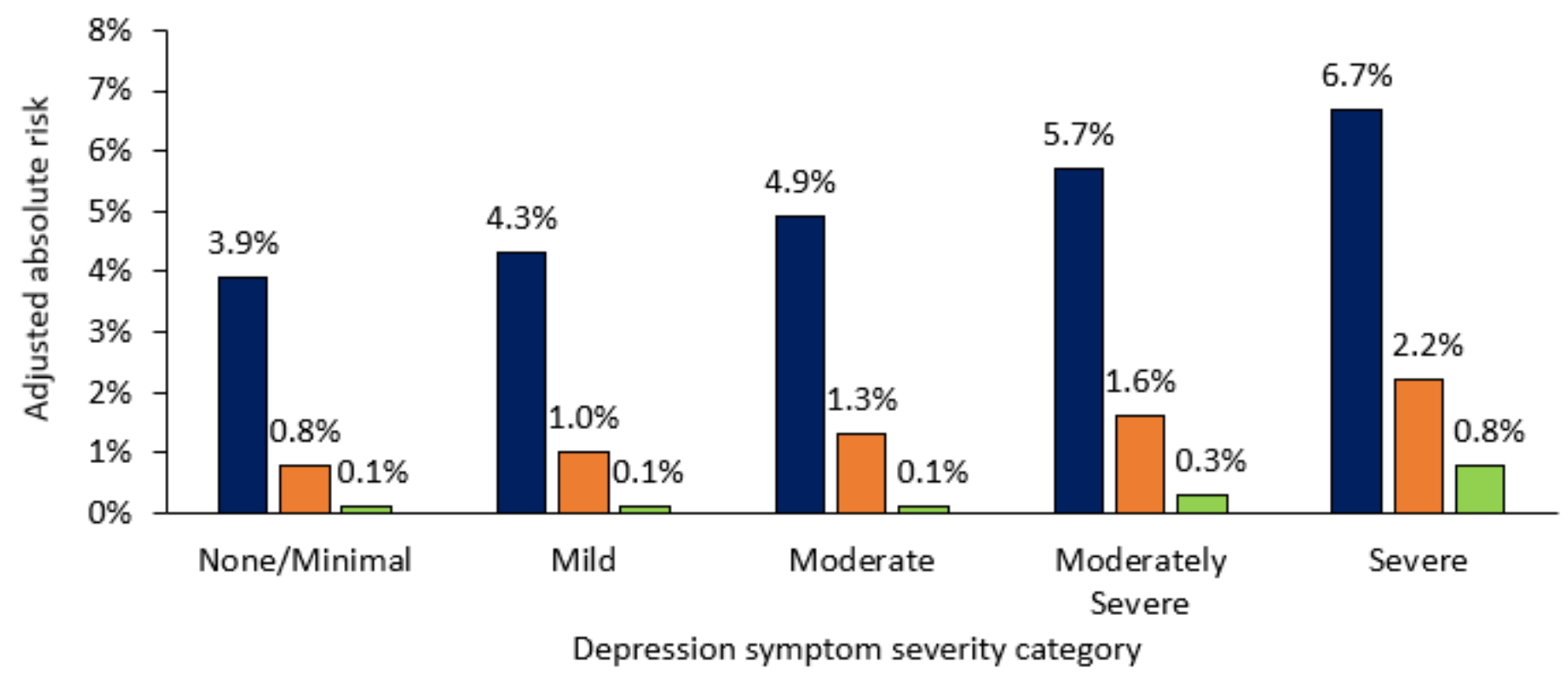

Figure 1

Adjusted absolute risks of all-cause, MDD-related, and SI/SA-related initial hospital encounters following a PHQ-9 assessment MDD: Major depressive disorder; SA: Suicide attempt; SI: Suicidal ideation 


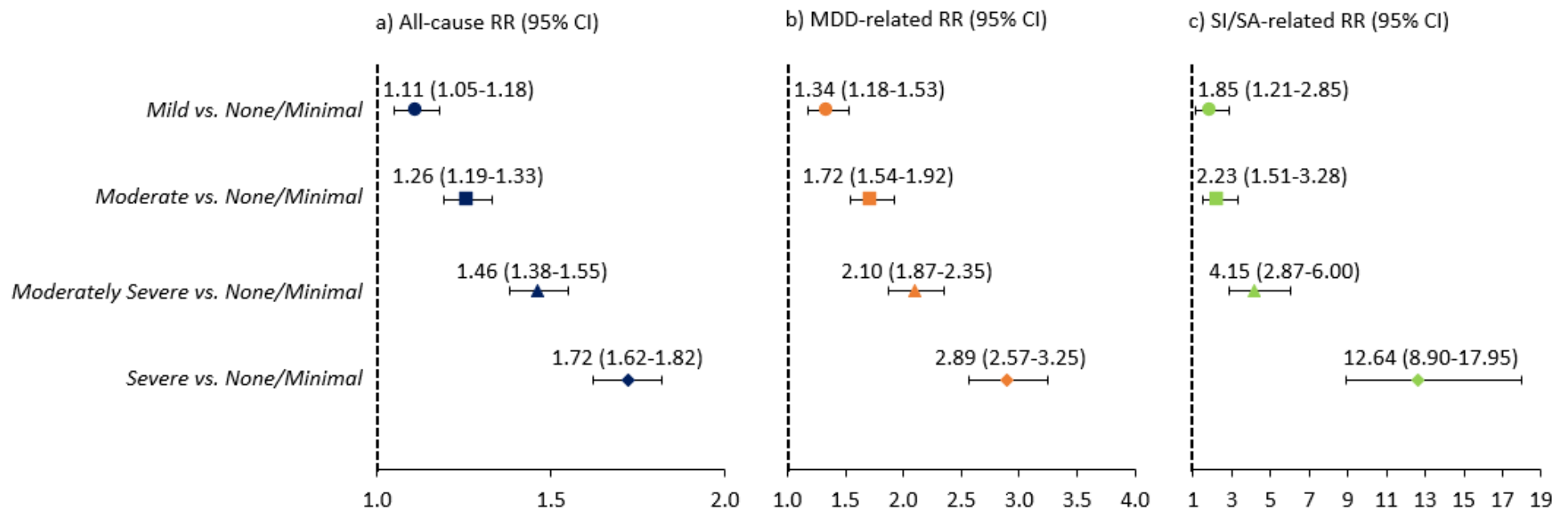

Figure 2

Adjusted relative risks of a) all-cause, b) MDD-related, and c) SI/SA-related initial hospital encounters following a PHQ-9 assessment P-values for all comparisons were $<0.01$. For panels $a, b$, and $c$, the $x$-axes are in different scales. Cl: Confidence interval; MDD: Major depressive disorder; RR: Relative risk; SA: Suicide attempt; SI: Suicidal ideation 